\title{
Evaluation of the effectiveness of the Quadratus Lumborum Block type I using ropivacaine in postoperative analgesia after a cesarean section - a controlled clinical study
}

\author{
Marcin Mieszko Mieszkowski ${ }^{1,2}$, Ewa Mayzner-Zawadzka², Bułat Tuyakovi, 3 , \\ Marta Mieszkowska ${ }^{3}$, Maciej Żukowski ${ }^{4}$, Tomasz Waśniewski ${ }^{5}$, Dariusz Onichimowski ${ }^{1,2}$ \\ ${ }^{1}$ The Clinical Department of Anesthesiology and Intensive Care, Voivodal Specialistic Hospital, Olsztyn, Poland \\ ${ }^{2}$ Department of Anesthesiology and Intensive Care, Collegium Medicum, Faculty of Medicine, University of Warmia and Mazury, \\ Olsztyn, Poland \\ ${ }^{3}$ Department of Surgery, Faculty of Medical Sciences,, University of Warmia and Mazury, Olsztyn, Poland \\ ${ }^{4}$ The Clinical Department of Gynecology and Obstetrics, Municipal Polyclinical Hospital, Olsztyn, Poland \\ ${ }^{5}$ Department of Gynecology and Obstetrics, Collegium Medicum, Faculty of Medicine, University of Warmia and Mazury,
} Olsztyn, Poland

\begin{abstract}
Objectives: Quadratus Lumborum Block in contrast to Transversus Abdominis Plane Block contains a unique component which not only stops somatic pain but also inhibits visceral pain by spreading the local anesthetic to the paravertebral space. This study was designed to determine whether performing the Quadratus Lumborum Block type I in patients undergoing cesarean section would be associated with both decreased morphine consumption and decreased pain levels in the postoperative 48-hour period.

Material and methods: Sixty patients undergoing caesarean section under spinal anesthesia were randomly and equally assigned to one or other of two groups: QLB I (who received Bilateral Quadratus Lumborum Block type I with the use of $24 \mathrm{~mL}$ 0.375\% ropivacaine per side) or a Control group. In both groups, on-demand morphine analgesia was administered postoperatively within the first 48 hours. The following were measured: the morphine consumption; the time elapsed from the C-section until the first dose of morphine; and the levels of pain intensity among patients in rest (numeral pain rating scale). Results: There were no statistically significant demographic data differences between the QLB I and Control groups. The following significant differences were observed in the 48-hour postoperative period: morphine consumption was higher in the Control group $(p=0.000)$; the time elapsed from the $C$-section until the first dose of morphine was longer in QLB I group $(p<0.05)$; and the median of the pain numeric rating scale was higher in the Control group $(p<0.05)$.

Conclusions: Quadratus Lumborum Block type I significantly reduces morphine consumption and pain levels up to 48 hours postoperatively.
\end{abstract}

Key words: quadratus lumborum block type I, ropivacaine, cesarean section, multimodal analgesia

Ginekologia Polska 2018; 89, 2: 89-96

\section{INTRODUCTION}

A cesarean section is the most commonly performed surgery in gynecology and obstetrics in the world, which is a steadily increasing trend [1]. The intensity of postoperative acute pain among patients after a $\mathrm{C}$-section results from the development of somatic and visceral pain which occurs due to cutting the structures of the abdominal wall and the uterus [2,3]. Unsuccessfully conducted analgesia after a C-section results in considerable suffering in newly delivered mothers, who consequently may be less willing to feed and care for the new-born [4, 5]. Additionally, unsuccessfully conducted analgesia may impair early ambulation 
and it poses one of the risk factors for chronic pain in the abdomen, and pelvis [6]. To achieve effective analgesia, a multimodal strategy should be used with simultaneously administered painkillers from all three levels of the analgesic ladder in conjunction with specialized peripheral nerve block techniques and with either continuous epidural or spinal anesthesia [7, 8]. For several years now, one can notice a real renaissance in regional anesthesia of the anterolateral abdominal wall after a C-section, mainly due to the introduction of ultrasonography (USG) during nerve block procedures [9]. This has resulted in numerous studies proving its effectiveness, mainly through the reduction of somatic components of postoperative pain [10]. Currently, the most popular regional block after a $\mathrm{C}$-section is Transversus $\mathrm{Ab}$ dominis Plain Block (TAPB) [10-12]. Dozens of clinical trials and their meta-analyses show that TAPB, as a component of multimodal pain therapy, provides effective analgesia after a C-section within the field of somatic pain which in fact is only coming from the abdominal wall [10-12]. Conducting research on a new access to TAPB using ultrasound led to the Quadratus Lumborum Block (QLB) $[13,14]$. A unique component of the QLB is not only that it stops somatic pain but also that it inhibits visceral pain due to the spread of the local anesthetic to the paravertebral space. The analgesic's effectiveness and superiority overTAPB after a C-section from a posterior approach (QLB II) were shown by Blanco [14-16]. We hypothesized that QLB type I as part of a multimodal analgesic regimen would result in decreased opioid consumption and improved analgesia in the first 48 hours after a $\mathrm{C}$-section. The aim of this study was to test this hypothesis and to observe any side effects in patients undergoing elective $\mathrm{C}$-section via Pfannenstiel abdominal wall incision under spinal anesthesia.

\section{MATERIAL AND METHODS}

After approval from the Bioethics Committee at the University of Warmia and Mazury, on 25 June 2014, reference number 21/2014, written informed consent was obtained from 60 ASA II patients scheduled for elective C-sections via Pfanenstiel incision under spinal anesthesia. The exclusion criteria were as follows: any history of relevant drug allergy/sensitivity; pregnancy-induced hypertension; gestation diabetes mellitus; coagulopathy; anatomical abnormalities of abdomen; and abuse of tranquilizers, paracetamol or opioids. Patients were randomised by using a website (http://www.randomization.com) and a computer-generated table of unallocated numbers; thus, determining who would receive a bilateral Quadratus Luborum Block type I (QLB I group, $\mathrm{n}=30$ ) or be excluded from this block (Control group, $\mathrm{n}=30$ ). In the operating room, an intravenous cannula (a 16-gauge) was inserted in the hand or arm to all patients who were then monitored by electrocardiogram and non-invasive arterial blood pressure; and their peripheral pulse oximetry and diuresis were checked. Patients received spinal anesthesia in the sitting position at the L3-4 interspace with $12.5 \mathrm{mg}$ 0.5\% hyperbaric bupivacaine (Marcaine Heavy Spinal, Astra Zeneca) and $20 \mu \mathrm{g}$ fentanyl (Polfa Warszawa) injection. Afterwards, parturients were placed in the supine position with $15^{\circ}$ left uterine displacement. The crystalloids and ephedrine iv were administered as needed to treat hypotension. The oxygen supply was delivered through a facemask at $6 \mathrm{~L} / \mathrm{min}$. A C-section was permitted to proceed after Th 6 sensory block assessed by loss of cold and touch. Patients received an iv infusion of $10 \mathrm{IU}$ oxytocin (Gedeon Richter Plc.) after delivery and a prophylactic metoclopramide $10 \mathrm{mg}$ (Metoclopramidum $0,5 \%$, Polpharma) iv was administered. At the end of the surgery patients received paracetamol $1 \mathrm{~g}$ iv (Perfalgan, Bristol-Myers Squibb).

\section{Interventions}

After wound closure, in the patients allocated to the QLB I group, the Quadratus Lumborum Block I was performed using the following aseptic techniques. The patient was placed in the lateral position, the skin was sanitized with antiseptic solution. At the beginning a convex $6 \mathrm{MHz}$ ultrasound probe (BK Flex Focus 400) with a protective sheath was placed above the lateral edge of the rectus muscle and USG imaging depth and gain was set. Next, the probe was inserted in the intracranial direction towards the iliac crest until three bellies of abdominal muscles were visualized. Following the internal oblique and transversus abdominis muscles, the quadratus lumborum was identified with its adherent to the lateral edge of the transverse process of the L4 vertebral body and the intermediate layer of the thoracolumbar fascia. Also, the erector spinae muscle and psoas major muscle were visualized, together giving a recognisable pattern of a three-leaf shamrock well described in the Shamrock Block technique. A 20-guage $10 \mathrm{~mm}$ Stimuplex Ultra 360 needle (BBraun, Melsungen AG, Germany) was attached with $100 \mathrm{~mm}$ flexible tubing to a syringe filled with $0.9 \%$ saline and was inserted in-plane to the probe from medial to lateral and moved until the point of injection was placed at the anterolateral border of the QLM and above the junction with the transversalis fascia (Fig. 1). Then, $5 \mathrm{~mL}$ of $0.9 \%$ saline was injected to visualize the solution spread and to confirm the needle placement. Patients in the QLB I group received $24 \mathrm{~mL}$ of $0.375 \%$ ropivacaine (Ropimol, Molteni) per side (in total $180 \mathrm{mg}$ ) (Fig. 2). This solution was injected after aspiration in $4 \mathrm{~mL}$ increments. The identical technique was repeated on the opposite side. After the procedure, patients were transferred to the post-anesthesia care unit (PACU) where their heart rate, non-invasive arterial blood pressure, respiratory rate, peripheral pulse oximetry and dieresis were 


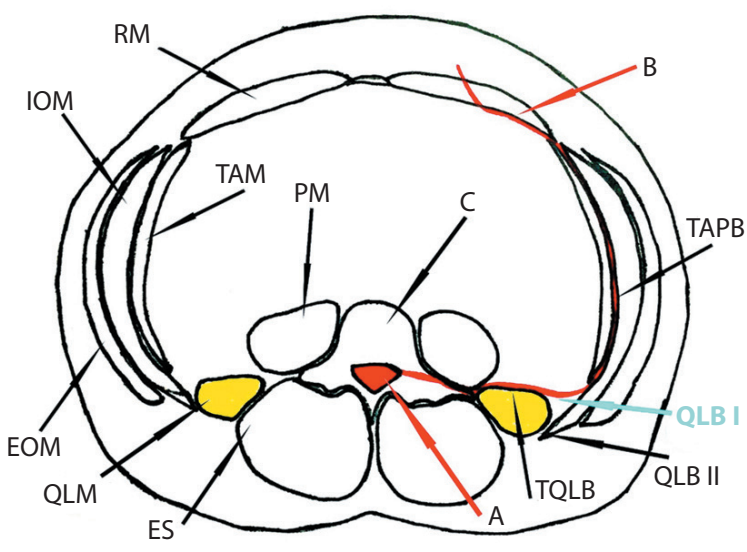

Figure 1. Diagram of abdomen cross section above the iliac crest (L4) TQLB - Transmuscular Quadratus Lumborum Block; QLB — Quadratus Lumborum Block type I \& II, TAPB — Transversus Abdominis Plane Block; A — spinal cord; $B$ - ventral ramus of spinal nerve; $C$ - body of lumbar vertebral (L4); ES - erector spinae muscle; PM — psoas major muscle; QLM — quadratus lumborum muscle; EOM — external oblique muscle; IOM — internal oblique muscle; TAM — transversus abdominis muscle; RM - rectus abdominis muscle

measured. Nurses providing postoperative care were given no information about which patient belonged to which study group. Over the next 48 hours, all patients received $1 \mathrm{~g}$ of paracetamol iv at constant intervals of time (every 6 hours) and $5 \mathrm{mg}$ of morphine subcutaneously depending on their intensity of pain (NRS > 3), or, on demand with the proviso of a 4-hour administration frequency. Next, the the level of pain intensity was evaluated, only in rest among the newly delivered mothers (using NRS scale 0-10 in which $0=$ no pain and $10=$ worst pain imaginable) and consecutively after 2, 4, 8, 12, 16, 20, 24, 30, 36, 42 and 48 hours. At every postoperative time-point the following parameters were measured: sedation (Ramsey scale); nausea, vomiting and itching ( $0=$ none, $1=$ mild, $2=$ moderate, $3=$ severe); the possibility of the free movement of limbs or any other possible side effects. The primary outcome measure in this clinical study was $48 \mathrm{~h}$ morphine consumption. Secondary outcome measures included NRS scores, time elapsed to the first request for morphine and any side effects associated with morphine consumption and the block technique.

\section{Statistical analysis}

Reviewing the literature in 2014, we did not identify any previous studies comparing QLB type I or II with $48 \mathrm{~h}$ morphine consumption or NRS pain scores after $\mathrm{C}$-section. The minimum patient number in each study group was calculated based on the data from the pilot study of 10 patients, in whom the $24 \mathrm{~h}$ morphine requirement was $25 \mathrm{mg}$. We considered that a clinically important difference in $24 \mathrm{~h}$ morphine consumption would be a $25 \%$ absolute reduction in the QLB I group compared with the control group. We elected to recruit 30 patients per group into the study based on a calculation of 0.05 and a power of 0.8 , to

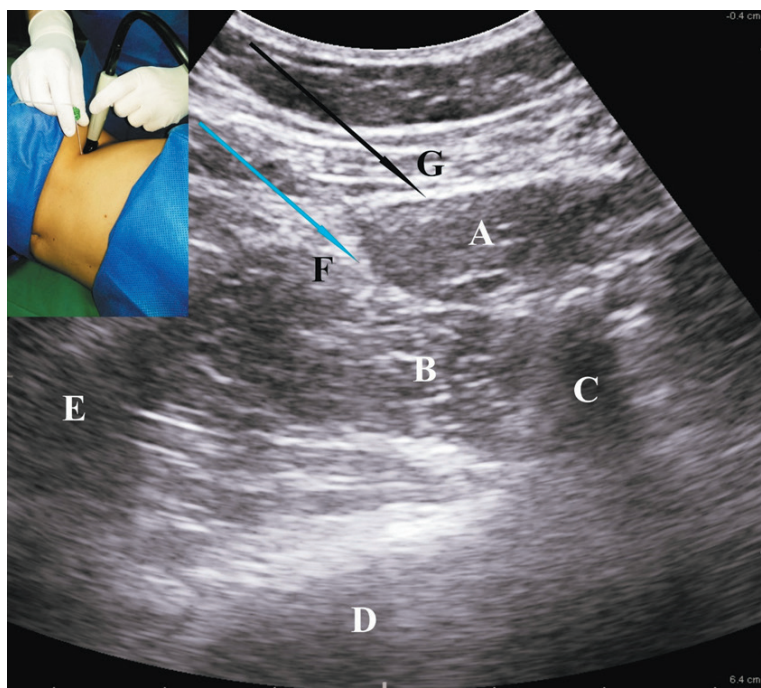

Figure 2. Ultrasound-guided Quadratus Lumborum Block Type I i II (QLB I i QLB II)

minimize any effect of data loss,. The results were analysed by using SPSS Statistics (ver. 19, SPSS Inc, USA) and taking as the level of significance $p=0.05$. Data was assessed for normality based on the results of the Shapiro-Wilk test. Statistical descriptions of the analysed variables included the numerical amount, the minimum and maximum value, median, mean and standard deviation. In the case where the variables exhibited a normal distribution, a parametric t-Student test was used in two independent groups. In turn, when distributed values were different from normal, a non-parametric Mann-Whitney $U$ test was applied. The Chi-square test was used to compare differences between the variables obtained.

\section{RESULTS}

Sixty patients were enrolled in the study. Two patients from the QLB I group were excluded because of postoperative analgesic protocol violations, so results for fifty-eight patients were analyzed in total (Fig. 3). The groups did not differ in terms of demographic data (Tab. 1). Our study compares the two groups' morphine consumption, by comparing morphine use across the 48-hour period; and by comparing consumption between day 0 and day 1 ; to identify statistically significant differences (Tab. 2). In the group of patients who underwent the QLB I block, there was a statistically lower use of morphine at 4-hour intervals, in contrast with the control group (Tab. 3). Another statistically significant difference between the groups was the time elapsed from the $\mathrm{C}$-section until the first dose of morphine, which amounted to 222 minutes on average in the Control group and 618 minutes in the QLB I group (Tab. 4). Statistically significant differences were also demonstrated between the two study groups when assessing 


\section{O N S O R T}

TRANSPARENT REPORTING of TRIALS

CONSORT 2010 Flow Diagram

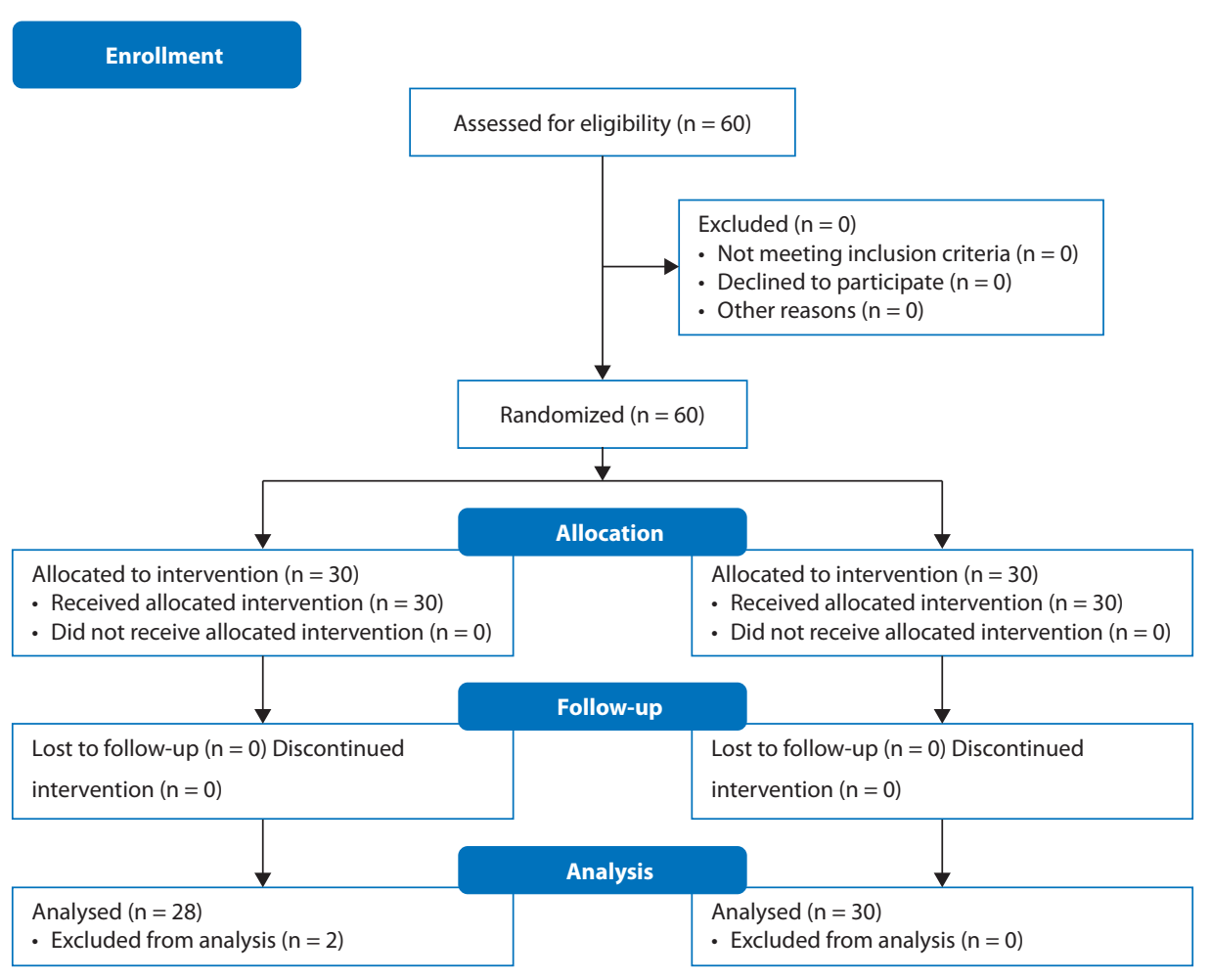

Figure 3. Consort statement

\begin{tabular}{|c|c|c|c|c|c|c|c|c|c|}
\hline & \multicolumn{4}{|c|}{ Control group $(\mathrm{N}=30$ ) } & \multicolumn{4}{|c|}{ QLB I group $(N=28)$} & \multirow{2}{*}{$P$ value } \\
\hline & Median & Mean & SD & $95 \% \mathrm{Cl}$ & Median & Mean & SD & $95 \% \mathrm{Cl}$ & \\
\hline Height [cm] & 167.50 & 167.80 & 5.64 & $165.69-169.91$ & 165.00 & 166.71 & 4.93 & $164.80-168.63$ & 0.39 \\
\hline Weight [kg] & 85.00 & 82.57 & 14.26 & $77.24-87.89$ & 80.00 & 79.96 & 9.79 & $76.17-83.76$ & 0.44 \\
\hline Age [years] & 29.15 & 29.29 & 4.55 & $27.59-30.99$ & 27.800 & 28.746 & 3.25 & $27.49-30.01$ & 0.82 \\
\hline BMI $\left[\mathrm{kg} / \mathrm{m}^{2}\right]$ & 32 & 30.63 & 4.85 & $28.82-32.45$ & 31 & 30.43 & 4.09 & $28.84-32.01$ & 0.64 \\
\hline
\end{tabular}

SD — standard deviation; QLB — Quadratus Lumborum Block

\begin{tabular}{|l|c|c|c|c|c|c|c|c|}
\hline & Table 2. Cumulative use of morphine with the division on day $\mathbf{0}$ and 1, and a total of 48 hours \\
\hline & \multicolumn{3}{|c|}{ Control group (N = 30) } & \multicolumn{4}{c|}{ QLB I group (N = 28) } \\
\hline & Mean range & Range & Median & Mean range & Range & Median & P value \\
\hline Morphine use (mg) day 0 & 41.1 & 1233 & 20 & 17.07 & 478 & 10 & 0.0000 \\
\hline Morphine use (mg) day 1 & 36.6 & 1098 & 10 & 21.89 & 613 & 5 & 0.0001 \\
\hline Morphine total dose (mg) 48hours & 41.77 & 1253 & 30 & 16.36 & 458 & 15 & 0.0000 \\
\hline
\end{tabular}

QLB - Quadratus Lumborum Block 


\begin{tabular}{|c|c|c|c|}
\hline & Control group $(\mathrm{N}=30)$ & QLB I group ( $\mathrm{N}=28)$ & \\
\hline 4-hour intervals & No (\%) who use morphine & No (\%) who use morphine & P value \\
\hline $0-4 \mathrm{~h}$ & $20(67 \%)$ & $0(0 \%)$ & $p<0.05$ \\
\hline $4-8 h$ & $23(77 \%)$ & $2(7 \%)$ & $p<0.05$ \\
\hline $8-12 h$ & $22(73 \%)$ & $22(79 \%)$ & $P=0.64$ \\
\hline $12-16 \mathrm{~h}$ & $20(67 \%)$ & $10(36 \%)$ & $p<0.05$ \\
\hline $16-20 h$ & $18(60 \%)$ & 17 (61\%) & $p=0.96$ \\
\hline $20-24 h$ & $10(33 \%)$ & $11(39 \%)$ & $p=0.64$ \\
\hline $24-28 h$ & $17(57 \%)$ & $6(21 \%)$ & $p<0.05$ \\
\hline $28-32 \mathrm{~h}$ & $16(53 \%)$ & $7(25 \%)$ & $p<0.05$ \\
\hline $32-36 h$ & $18(60 \%)$ & $6(21 \%)$ & $p<0.05$ \\
\hline $36-40 h$ & $6(20 \%)$ & $3(11 \%)$ & $p=0.33$ \\
\hline $40-44 \mathrm{~h}$ & $5(17 \%)$ & $3(11 \%)$ & $p=0.51$ \\
\hline $44-48 h$ & $0(0 \%)$ & $2(7 \%)$ & $p=0.14$ \\
\hline
\end{tabular}

QLB - Quadratus Lumborum Block

\begin{tabular}{|c|c|c|c|c|c|c|c|c|c|c|c|}
\hline & \multicolumn{5}{|c|}{ Control group ( $N=30$ ) } & \multicolumn{5}{|c|}{ QLB I group ( $N=25)$} & \multirow{2}{*}{ P value } \\
\hline & Min & Max & Median & Mean & SD & Min & Max & Median & Mean & SD & \\
\hline Time (min.) & 95 & 425 & 202.5 & 221.67 & 77.96 & 330 & 990 & 630 & 618.4 & 128.21 & $p=0.000$ \\
\hline
\end{tabular}

SD — standard deviation

\begin{tabular}{|c|c|c|c|c|c|}
\hline \multirow{2}{*}{ NRS at rest $(0-10)$} & \multicolumn{2}{|c|}{ Control group $\left(\mathrm{N}_{\mathrm{S}}=30\right)$} & \multicolumn{2}{|c|}{ QLB I group (N. = 28) } & \multirow{2}{*}{ P value } \\
\hline & Median & Variance & Median & Variance & \\
\hline $0 \mathrm{~h}$ postoperative & $0(0-0)$ & 0.000 & $0(0-0)$ & 0.000 & NS \\
\hline $2 \mathrm{~h}$ & $3(2-4)$ & 0.372 & $0(0-2)$ & 0.476 & $p=0.000$ \\
\hline $4 \mathrm{~h}$ & $3(0-7)$ & 1.131 & $1(0-4)$ & 1.053 & $p=0.000$ \\
\hline $8 \mathrm{~h}$ & $3(2-5)$ & 0.574 & $2(0-3)$ & 0.847 & $p=0.000$ \\
\hline $12 \mathrm{~h}$ & $3(2-6)$ & 0.740 & $2(0-3)$ & 0.513 & $p=0.000$ \\
\hline $16 \mathrm{~h}$ & $3(1-6)$ & 1.306 & $2(1-4)$ & 0.851 & $p=0.001$ \\
\hline $20 \mathrm{~h}$ & $3(2-5)$ & 0.516 & $2(0-4)$ & 0.804 & $p=0.000$ \\
\hline $24 \mathrm{~h}$ & $3(1-6)$ & 0.861 & $2(0-3)$ & 0.757 & $p=0.000$ \\
\hline $30 \mathrm{~h}$ & $3(2-5)$ & 0.547 & $1(0-3)$ & 0.630 & $p=0.000$ \\
\hline $36 \mathrm{~h}$ & $3(2-5)$ & 0.648 & $1(0-4)$ & 0.988 & $p=0.000$ \\
\hline $42 \mathrm{~h}$ & $2(1-4)$ & 0.616 & $1(0-3)$ & 0.670 & $p=0.000$ \\
\hline $48 \mathrm{~h}$ & $1(0-3)$ & 0.340 & $0(0-1)$ & 0.247 & $p=0.000$ \\
\hline
\end{tabular}

IQR — interquartile range; NS — not sagnificant; QLB — Quadratus Lumborum Block

the levels of intensity of pain reported by patients, using the NRS scale at these intervals: after $2,4,8,12,16,20,24$, $30,36,42$, and 48 hours from the C-section (Tab. 5). No difference was noticed between the groups when it came to sedation, nausea, vomiting and itching; or free limb movement or other possible side effects.

\section{DISCUSSION}

Opioids continue to play an undisputed role in the treatment of acute pain after C-sections; most often applied systemically and/or into the subarachnoid space [17]. Intravenous administration of opioids is recommenced, using the Patient Controlled Analgesia method (PCA) $[4,8]$. In 
the opinion of numerous authors, the most effective and longest-lasting analgesic (11-24 hours) in the postoperative period among patients after a C-section, is exhibited by morphine used as a component of spinal anesthesia [17, 18]. The side effects and limits in systemic and intrathecal usage of opioids after a $\mathrm{C}$-section are: respiratory depression, nausea and vomiting, itching, excessive sedation, slowing peristaltic intestine activity and pruritus [19]. One cannot ignore the possibility of using Tramadol, which, in many cases of post-operative pain therapy after laparotomy, is more positive than morphine because, for example, there is less risk of pruritus and of respiratory depression [20]. Regional anesthesia used with non-opioid analgesics aims to reduce the total dose of opioids taken by patients during both the intra- and post-operative periods, which is the main point of multimodal analgesia [8].

Various analyses showed that the Transversus Abdominis Plane Block (TAPB) is an effective tool to fight postoperative pain in terms of reducing the total dose of opioids, but only when spinal morphine is not used [21, 22]. Carney et al. demonstrated, by using an MRI of the chest and abdomen, when comparing between four groups of volunteers, that the spread of LA after TAPB occurs only in the area of the transversus abdominis plane, determining a slowdown of only somatic pain and providing a sensory block only within the scope of the innervation of Th9-Th10 or Th11-L1. Conversely, the block within the QLM revealed the spread of the contrast towards the paravertebral space between Th4-L1 spaces [10, 13, 23]. The aim of our study was to confirm what Blanco indicated in 2007, that a new concept of the block of the abdominal wall of the inhibitory effect of somatic and visceral pain, the so called paravertebral block component, was beneficial $[14,15]$. There were no published studies evaluating the effectiveness of the QLB I and post-cesarean section until 2014, when the protocol of the clinical trial presented here was developed. According to various studies published since 2015, the QLB and its variants are an effective analgesic tool compared with the TAPB due to the absence of the paravertebral component; a smaller scope of activities; and the possibility of fewer complications $[15,16,24]$.

In the presented study the focus has been on the assessment of pain in the postoperative period during the first 48 hours (day 0 and 1 ) after a C-section. Among other researchers, the most frequently used observation time was a 24-hour cycle [11]. In contrast, the evaluation of pain intensity for a period of 48 hours after a C-section, was conducted among some authors after applying TAPB; and by Blanco at al. after application of QLB II [14, 18, 25]. One of the main methods of assessing the effectiveness of analgesic QLB I was to compare the use of morphine for patients in two study groups $[11,14]$. In our study of a Control group and the QLB I group, the median of the total morphine dose administered subcutaneously in the first 24 hours was $20 \mathrm{mg}$ and $10 \mathrm{mg}$ respectively; and during the first 48 hours $30 \mathrm{mg}$ and $15 \mathrm{mg}$ respectively. This result compares with other authors'studies which evaluated morphine consumption by PCA iv during the first 24 hours, where performing the QLB II or TAPB had results of $7.5 \mathrm{mg}, 18 \mathrm{mg}, 19 \mathrm{mg}$ and $25 \mathrm{mg}$ across the different studies [14, 21, 22, 26].

A comparison of our study's two research groups' results for the four-hourly intervals gave interesting results. During the first 8 hours after a C-section as many as 70\% more patients took morphine in the control group comparing with the QLB I group. Then, also worth noting is the period between 8 and 12 hours after the C-section, where conversely, the morphine consumption was higher by $6 \%$ in the QLB I group. This sudden change in the morphine demand by the QLB I group from 7\% to $79 \%$, and the constancy in the control group $(77 \%$ and $73 \%$ respectively for the two periods), clearly indicates the period when the effects of the analgesic block disappeared. The difference in the timing of the QLB I group's morphine requirement is reflected in the calculated difference of the timing of the first dose of morphine (10 hours and 18 minutes on average); compared with that of the Control group which was at 3 hours and 42 minutes on average. The next period of morphine usage in the Control group was statistically higher than the QLB I group by $30 \%$ and was observed between the 12 and 16 hours; and again between 24 and 36 hours from the time of the $\mathrm{C}$-section. This difference, occurring during the first 12 hours of the second day, may suggest that the QLB I patients experienced less pain after night time due to a reduction of the first stage of postoperative pain by the use of block, and thus, may indicate that the use of the block could help to reduce pain for a further period of the patient's hospital stay [27].

The author applied the NRS scale to the subjective assessment of pain intensity among patients. Among other researchers of analgesic efficacy of TAPB and QLB after a C-section, VAS was the most frequently used scale [28]. The comparison of pain intensity assessments between the two groups in our study showed that in the Control group the maximum pain intensity rating reached 7 points with a median of 3 points; while in the QLB group the maximum pain intensity rating did not exceed 4 points, with a median between 1 and 2 points. Much better results from the VAS scoring was reported by Blanco et al., where, for the QLB group, the maximum pain intensity score was 3 points, with a median of 0 ; and in the Control group the maximum pain intensity score was 5 points, with a median of 3 points [29]. According to the recommendations of Hartrick et al., and Noblet et al., the pain therapy is well run in the postoperative period if the assessment of NRS or VAS does not exceed 
3 points [29, 30]. Our literature review shows that many other authors of clinical trials of postoperative analgesia after a C-section also struggled with insufficiently effective pain treatment, showing results of NRS or VAS $>3$ [31]. The more favorable results obtained by Blanco et al. for both the assessment of pain intensity using the VAS scale and the total consumption of morphine, especially in the first 12 hours in both study groups, arose mainly from the lack of the use of a controlled analgesia by the patient (PCA) [14].

The differences between our findings and those of Blanco et al. may also occur due to the different place at which the deposit of LA is made within the QLM by Blanco et al., meaning more from the rear side, described as QLB II by Blanco and McDonnell [14]. In our study by contrast, the LA was deposited according to the original 2007 concept, i.e., from the side of the anterolateral abdominal wall and next to the fascia transversalis, which is QLB I [14, 16]. Another important difference between our study and that of Blanco et al., which can affect the outcome of the efficiency of analgesic QLB, was the type, concentration and volume of the LA used. In our study, to avoid the possible toxic effects of bupivacaine, which was used in the study by Blanco et al. and other authors, we performed the QLB by using the less-toxic ropivacaine (though of a weaker efficiency than bupivacaine), which had also often been used by other researchers working on the effectiveness of analgesic TAPB [22, 32].

During the study, there were no adverse effects of the QLB applied, the most dangerous of which could be the patient experiencing Local Anesthetic Systemic Toxicity (LAST) caused by intravascular administration of the LA or associated with exceeding a total dose of the LA [33]. Thanks to the performance of ultrasound and the aspiration manoeuvre, safety of the procedure was significantly increased [9, 34].

Among the limitations of our method, we must mention the failure of using the PCA method due to the lack of proper equipment. Another limitation was the subcutaneous supply of morphine on demand in the event of pain, with a constant dose of $5 \mathrm{mg}$ and a minimum time interval of 4 hours between doses. Perhaps a better comparison between our two study groups would be obtained by if the study was blinded, achieved by performing QLB in both groups, but by using $0.9 \% \mathrm{NaCl}$ solution in the Control group.

\section{CONCLUSIONS}

Considering the results of the statistical analysis, our observations and answers to the survey, it can be concluded that the method of the Quadratus Lumborum Block type I is a safe and well tolerated procedure by patients undergoing cesarean sections. Based on both subjective and objective methods for assessing pain intensity, it was indicated that
QLB I significantly reduced pain among patients. There was no occurrence of any danger to life or health side effects associated with the implementation of the QLB I block or due to the use of ropivacaine.

\section{Acknowledgments \\ None}

\section{REFERENCES}

1. OECD Health Statistics 2014 - Frequently Requested Data. http://www. oecd.org/els/health-systems/oecd-health-statistics-2014-frequentlyrequested-data.htm.

2. Granot M, Lowenstein L, Yarnitsky D, et al. Postcesarean section pain prediction by preoperative experimental pain assessment. Anesthesiology. 2003; 98(6): 1422-1426, doi: 10.1097/00000542-200306000-00018, indexed in Pubmed: 12766652 .

3. Strigo IA, Bushnell MC, Boivin M, et al. Psychophysical analysis of visceral and cutaneous pain in human subjects. Pain. 2002; 97(3): 235-246, doi: 10.1016/s0304-3959(02)00023-4, indexed in Pubmed: 12044620.

4. Gadsden J, Hart S, Santos AC. Post-cesarean delivery analgesia Anesth Analg. 2005; 101(5 Suppl): S62-S69, doi: 10.1213/01. ane.0000177100.08599.c8, indexed in Pubmed: 16334493.

5. Karlström A, Engström-Olofsson R, Norbergh KG, et al. Postoperative pain after cesarean birth affects breastfeeding and infant care. J Obstet Gynecol Neonatal Nurs. 2007; 36(5): 430-440, doi: 10.1111/j.1552-6909.2007.00160.x, indexed in Pubmed: 17880313.

6. Eisenach JC, Pan PH, Smiley R, et al. Severity of acute pain after childbirth, but not type of delivery, predicts persistent pain and postpartum depression. Pain. 2008; 140(1): 87-94, doi: 10.1016/j.pain.2008.07.011, indexed in Pubmed: 18818022

7. Lavoie A, Toledo P. Multimodal postcesarean delivery analgesia. Clin Perinatol. 2013; 40(3): 443-455, doi: 10.1016/j.clp.2013.05.008, indexed in Pubmed: 23972750.

8. Misiołek H, Cettler M, Woron J, et al. The 2014 guidelines for post-operative pain management. Anaesthesiol Intensive Ther. 2014; 46(4): 221-244, doi: 10.5603/AIT.2014.0041, indexed in Pubmed: 25293474.

9. Marhofer $P$, Willschke $H$, Greher $M$, et al. New perspectives in regional anesthesia: the use of ultrasound-past, present, and future. Can J Anesth. 2005; 52(S1): R28-R32, doi: 10.1007/bf03023081.

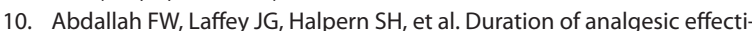
veness after the posterior and lateral transversus abdominis plane block techniques for transverse lower abdominal incisions: a meta-analysis. $\mathrm{Br}$ J Anaesth. 2013; 111(5): 721-735, doi: 10.1093/bja/aet214, indexed in Pubmed: 23811424.

11. Abdallah FW, Chan VW, Brull R. Transversus abdominis plane block: a systematic review. Reg Anesth Pain Med. 2012; 37(2): 193-209, doi: 10.1097/AAP.0b013e3182429531, indexed in Pubmed: 22286518.

12. Fusco $P$, Scimia $P$, Paladini $G$, et al. Transversus abdominis plane block for analgesia after Cesarean delivery. A systematic review. Minerva Anestesiol. 2015; 81(2): 195-204, indexed in Pubmed: 24739207.

13. Carney J, Finnerty O, Rauf J, et al. Studies on the spread of local anaesthetic solution in transversus abdominis plane blocks. Anaesthesia. 2011 66(11): 1023-1030, doi: 10.1111/j.1365-2044.2011.06855.x, indexed in Pubmed: 21851346.

14. Blanco R, Ansari T, Girgis E. Quadratus lumborum block for postoperative pain after caesarean section: A randomised controlled trial. Eur J Anaesthesiol. 2015; 32(11): 812-818, doi: 10.1097/EJA.0000000000000299, indexed in Pubmed: 26225500.

15. Blanco R, Ansari T, Riad W, et al. Quadratus Lumborum Block Versus Transversus Abdominis Plane Block for Postoperative Pain After Cesarean Delivery: A Randomized Controlled Trial. Reg Anesth Pain Med. 2016; 41(6): 757-762, doi: 10.1097/AAP.0000000000000495, indexed in Pubmed: 27755488.

16. Ueshima $\mathrm{H}$, Otake $\mathrm{H}$, Lin JA. Ultrasound-Guided Quadratus Lumborum Block: An Updated Review of Anatomy and Techniques. Biomed Res Int. 2017; 2017: 2752876, doi: 10.1155/2017/2752876, indexed in Pubmed: 28154824.

17. Weigl W, Bieryło A, Krzemień-Wiczyńska S, et al. [Comparative study of postoperative analgesia after intrathecal administration of bupivacaine with fentanyl or morphine for elective Caesarean section]. Anestezjol Intens Ter. 2009; 41(1): 28-32, indexed in Pubmed: 19517674. 
18. Kanazi GE, Aouad MT, Abdallah FW, et al. The analgesic efficacy of subarachnoid morphine in comparison with ultrasound-guided transversus abdominis plane block after cesarean delivery: a randomized controlled trial. Anesth Analg. 2010; 111(2): 475-481, doi: 10.1213/ANE.0b013e3181e30b9f, indexed in Pubmed: 20488929.

19. Abouleish E, Rawal N, Rashad MN. The addition of $0.2 \mathrm{mg}$ subarachnoid morphine to hyperbaric bupivacaine for cesarean delivery: a prospective study of 856 cases. Reg Anesth. 1991; 16(3): 137-140, indexed in Pubmed: 1883770.

20. Moore RA, McQuay HJ, Tomaszewski J, et al. Dexketoprofen/tramadol $25 \mathrm{mg} / 75 \mathrm{mg}$ : randomised double-blind trial in moderate-to-severe acute pain after abdominal hysterectomy. BMC Anesthesiol. 2016; 16: 9, doi: 10.1186/s12871-016-0174-5, indexed in Pubmed: 26801905.

21. Baaj JM, Alsatli RA, Majaj HA, et al. Efficacy of ultrasound-guided transversus abdominis plane (TAP) block for postcesarean section delivery analgesia--a double-blind, placebo-controlled, randomized study. Middle East J Anaesthesiol. 2010; 20(6): 821-826, indexed in Pubmed: 21526667.

22. Belavy D, Cowlishaw PJ, Howes M, et al. Ultrasound-guided transversus abdominis plane block for analgesia after Caesarean delivery. $\mathrm{Br}$ J Anaesth. 2009; 103(5): 726-730, doi: 10.1093/bja/aep235, indexed in Pubmed: 19700776.

23. Carney J, Lane J, Quondamatteo $F$, et al. Defining the Limits and the Spread Beyond the Transversus Abdominis Plane Block - Radiological and Anatomical Study. Reg Anesth Pain Med. 2008; 33(Sup 1): e7, doi: 10.1097/00115550-200809001-00013.

24. Dam M, Moriggl B, Hansen CK, et al. The Pathway of Injectate Spread With theTransmuscular Quadratus Lumborum Block: A Cadaver Study. Anesth Analg. 2017; 125(1): 303-312, doi: 10.1213/ANE.0000000000001922, indexed in Pubmed: 28277325.

25. McDonnell JG, Curley G, Carney J, et al. The analgesic efficacy of transversus abdominis plane block after cesarean delivery: a randomized controlled trial. Anesth Analg. 2008; 106(1): 186-91, table of contents, doi: 10.1213/01.ane.0000290294.64090.f3, indexed in Pubmed: 18165577.
26. Eslamian L, Jalili $Z$, Jamal A, et al. Transversus abdominis plane block reduces postoperative pain intensity and analgesic consumption in elective cesarean delivery under general anesthesia. J Anesth. 2012; 26(3): 334-338, doi: 10.1007/s00540-012-1336-3, indexed in Pubmed: 22354671.

27. Angle PJ, Halpern SH, Leighton $\mathrm{BL}$, et al. A randomized controlled trial examining the effect of naproxen on analgesia during the second day after cesarean delivery. Anesth Analg. 2002; 95(3): 741-5, table of contents, doi: 10.1213/00000539-200209000-00038, indexed in Pubmed: 12198063.

28. Mishriky BM, George RB, Habib AS. Transversus abdominis plane block for analgesia after Cesarean delivery: a systematic review and meta-analysis. Can J Anaesth. 2012; 59(8): 766-778, doi: 10.1007/s12630012-9729-1, indexed in Pubmed: 22622954.

29. Hartrick CT, Kovan JP, Shapiro $S$. The numeric rating scale for clinical pain measurement: a ratio measure? Pain Pract. 2003; 3(4): 310-316, doi: 10.1111/j.1530-7085.2003.03034.x, indexed in Pubmed: 17166126.

30. Noblet J, Plaat F. Raising the standard... to unachievable heights? Anaesthesia. 2010; 65(1): 88-89, doi: 10.1111/j.1365-2044.2009.06175.x, indexed in Pubmed: 20121782

31. Halpern S, Yee J, Oliver C, et al. Pain relief after cesarean section: A prospective Cohort study. Can J Anesth. 2007; 54(S1): 44214-44214, doi: 10.1007/bf03019915.

32. Costello JF, Moore AR, Wieczorek PM, et al. The transversus abdominis plane block, when used as part of a multimodal regimen inclusive of intrathecal morphine, does not improve analgesia after cesarean delivery. Reg Anesth Pain Med. 2009; 34(6): 586-589, doi: 10.1097/aap.0b013e3181b4c922, indexed in Pubmed: 19916252.

33. Griffiths JD, Le NV, Grant S, et al. Symptomatic local anaesthetic toxicity and plasma ropivacaine concentrations after transversus abdominis plane block for Caesarean section. Br J Anaesth. 2013; 110(6): 996-1000, doi: 10.1093/bja/aet015, indexed in Pubmed: 23454825.

34. Tuyakov B, Braczkowska M, Mieszkowski $M$, et al. Training in regional anesthesia. Pol Ann Med. 2016; 23(1): 80-85, doi: 10.1016/j.poamed.2015.12.005. 